\title{
Mortality of Youth Offenders Along a Continuum of Justice System Involvement
}

\author{
Matthew C. Aalsma, PhD, ${ }^{1}$ Katherine S.L. Lau, PhD, ${ }^{1}$ Anthony J. Perkins, MS, ${ }^{2}$ \\ Katherine Schwartz, JD, MPA, ${ }^{1}$ Wanzhu Tu, PhD, ${ }^{3}$ Sarah E. Wiehe, MD, MPH, ${ }^{4}$ \\ Patrick Monahan, PhD, ${ }^{3}$ Marc B. Rosenman, $\mathrm{MD}^{4}$
}

\begin{abstract}
Introduction: Black male youth are at high risk of homicide and criminal justice involvement. This study aimed to determine how early mortality among youth offenders varies based on race; gender; and the continuum of justice system involvement: arrest, detention, incarceration, and transfer to adult courts.

Methods: Criminal and death records of 49,479 youth offenders (ages 10-18 years at first arrest) in Marion County, Indiana, from January 1, 1999, to December 31, 2011, were examined. Statistical analyses were completed in November 2014.

Results: From 1999 to 2011 (aggregate exposure, 386,709 person-years), 518 youth offender deaths occurred. The most common cause of death was homicide (48.2\%). The mortality rate of youth offenders was nearly 1.5 times greater than that among community youth (standardized mortality ratio, 1.48). The youth offender mortality rate varied depending on the severity of justice system involvement. Arrested youth had the lowest rate of mortality $(90 / 100,000)$, followed by detained youth $(165 / 100,000)$; incarcerated youth (216/100,000); and youth transferred to adult court (313/ 100,000). A proportional hazards model demonstrated that older age, male gender, and more severe justice system involvement 5 years post-arrest predicted shorter time to mortality.
\end{abstract}

Conclusions: Youth offenders face greater risk for early death than community youth. Among these, black male youth face higher risk of early mortality than their white male counterparts. However, regardless of race/ethnicity, mortality rates for youth offenders increase as youth involvement in the justice system becomes more protracted and severe. Thus, justice system involvement is a significant factor to target for intervention.

(Am J Prev Med 2015;(I):III-nII) @ 2015 American Journal of Preventive Medicine

\section{Introduction}

$\mathrm{E}$ pidemiologic studies of detained and incarcerated youth have commonly found offenders die at much higher rates than community youth. ${ }^{1-5}$ In a longitudinal study of detained youth in Cook County, Illinois, the mortality rate of detained youth was four times that of the general adolescent population, ${ }^{5}$ and the increased risk of early mortality persisted into young

From the ${ }^{1}$ Section of Adolescent Medicine, Department of Pediatrics, Indiana University School of Medicine, Indianapolis, Indiana; ${ }^{2}$ Precision Statistical Consulting, LLC, Indianapolis, Indiana; ${ }^{3}$ Department of Biostatistics, Indiana University School of Medicine, Indianapolis, Indiana; and ${ }^{4}$ Children's Health Services Research, Department of Pediatrics, Indiana University School of Medicine, Indianapolis, Indiana

Address correspondence to: Matthew C. Aalsma, PhD, Indiana University School of Medicine, 410 West 10th St., Rm 1001J, Indianapolis IN 46202. E-mail: maalsma@iu.edu.

0749-3797/\$36.00

http://dx.doi.org/10.1016/j.amepre.2015.08.030 adulthood. ${ }^{6}$ Deaths of both youth offenders and community youth are likely to be violent. Homicide, which is most often firearm-related, is the second-leading cause of death for all youth ages 15-24 years. ${ }^{7}$ The majority of deaths $(68 \%)$ among Cook County's detained youth were the result of homicide. ${ }^{6}$ The troubling nature of these findings is compounded by the wealth of evidence that both exposure to the justice system ${ }^{8-10}$ and risk of violent death are disproportionately experienced by black youth. ${ }^{7,11}$ When compared with individuals of other races/ethnicities, black male youth suffer the highest rate of homicide-related deaths. ${ }^{7,11}$

Previous studies of early mortality have focused on detained and incarcerated populations, rarely exploring the associations between less serious involvement in the system (i.e., arrest) and risk of death. ${ }^{3}$ In reality, the extent of youth exposure to the system varies along a continuum of severity (i.e., arrest, detention, incarceration, and transfer 
to adult court). For example, the chances of youth being arrested in the U.S. are one in three by age 23 years, ${ }^{12}$ making arrest a relatively common experience. Youth arrested for more-serious or repeated charges may warrant short-term placement (days or weeks) in local detention facilities before legal processing; long-term (months or years) incarceration in state-run facilities; or transfer to the adult criminal justice system. Each offender status along the continuum of justice system involvement (i.e., arrested, detained, incarcerated, transferred) is more severe than the last; increased system exposure is characterized by harsher sanctions, more restrictive placement, and less access to behavioral health services or other rehabilitative efforts common in the juvenile justice system. ${ }^{13-17}$

The objective of this study was to test the associations between the level of involvement in the justice system and youth mortality. The authors hypothesized that the annual mortality rate would increase incrementally by the severity of youth involvement in the system. They also hypothesized that owing to their over-representation at each level of justice system involvement, ${ }^{18}$ black male youth would be at greater risk for mortality than other youth at comparable levels of system involvement. ${ }^{7,11}$

\section{Methods}

Data were gathered for a retrospective cohort study of youth who were involved in the juvenile or adult criminal justice systems in Marion County, Indiana, between January 1, 1999, and December 31, 2011. Marion County is primarily urban and includes Indianapolis, the largest city in Indiana. According to 2010 Census data, Marion County residents were $65.2 \%$ white, $28.4 \%$ black, $9.3 \%$ Hispanic, and $5.9 \%$ other race/ethnicity. ${ }^{19}$ Electronic criminal and death records for each offender were retrieved from the date of the youth's first arrest through December 31, 2011. The Marion County Juvenile Superior Court and the Marion County Sheriffs Office provided all juvenile and adult criminal records, respectively. Electronic death records were extracted from the Regenstrief Medical Record System (RMRS). ${ }^{20,21}$

Youth criminal records were linked to death records using, first, a probabilistic matching algorithm, ${ }^{22}$ which paired records based on identifying information: first, middle, and last name; gender; month and year of birth; and Social Security Number. The research team reviewed three sets of such outputs to identify the threshold (in each three blocking schemes) above which it was estimated that a true match occurred. In order to improve this matching, a program developed by a subset of this Indiana University research team (A Burgess, S Hoch, and SE Wiehe) was used to help correctly tie together multiple pairs involving the same youth. Based on the probabilistic matching algorithms alone, 42,148 of the justice involved youth IDs were linked to 74,823 unique ("global") patient IDs stored in the RMRS. By running the additional program, the authors found $11 \%$ of the individual justice IDs were linked to two to four separate RMRS global IDs. The pairs associated with that $11 \%$ of the justice youth were reviewed intensively by study personnel and collapsed (merging, where necessary, multiple RMRS global IDs) into appropriately defined individuals. The intensive one-by-one review of gray zones and ambiguous situations further minimized false matches. Additional information regarding this approach is available from the study authors. This study was approved by the IRB of Indiana University-Purdue University Indianapolis.

\section{Measures}

Youth gender; age at first arrest; and race/ethnicity (white, black, Hispanic, or multiracial) were gathered from electronic criminal records. All sampled youth offenders were assigned to one of four mutually exclusive categories reflecting the continuum of justice system involvement-arrested, detained, incarcerated, or transferred-based on their most serious involvement with the justice system between 1999 and 2011. Specifically, arrested youth were referred to the juvenile court but were not detained, incarcerated, or transferred to adult courts during the study period. Detained youth were held in county-run detention centers for an average of 2 weeks, most often pre-adjudication or pre-disposition. Incarcerated youth were held, usually for months or years, in state-run juvenile prison facilities. Transferred youth were excluded from the juvenile justice system and associated services, and tried in adult court owing to the seriousness of alleged crimes. The death records of all youth offenders were retrieved from the RMRS, which receives mortality data from local hospitals, the Indiana State Department of Health, and the national Social Security Administration. Cause of death was gathered from the Marion County Coroner's Office death certificates for $77.2 \%$ of deceased offenders.

In order to compare the mortality rate of youth offenders to that of the general population, the total number of deaths by year, race, gender, and U.S. Census age category (10-14, 15-19, 20-24, and 25-29 years) were retrieved from Marion County Public Health Department data. As in previous work on mortality, ${ }^{23}$ youth offender deaths were subtracted from total community youth deaths. Data describing deaths of youth in the community by year, race, gender, and age category are available upon request.

\section{Statistical Analysis}

Statistical analyses were completed in November 2014. Descriptive statistics were calculated at first arrest. Annual mortality rates were calculated, per 100,000 person-years, by demographic characteristics (gender, age category, and race/ethnicity). The Rothman/ Greenland method was used to calculate the 95\% CIs for annual mortality rates. ${ }^{24}$ Standardized mortality ratios (SMRs) were calculated to adjust for the gender, race/ethnicity, and age distributions of community youth. The number of deaths in several race/ethnicity and age categories was small; hence, indirect standardization was used. The expected number of deaths was calculated by gender, race/ethnicity, and age categories for youth offenders, based on the community mortality rate of the corresponding category. The numbers of expected and observed deaths were aggregated across categories. The SMRs were calculated by dividing observed by expected deaths. Byar approximation was used to calculate 95\% CIs for SMRs and p-values testing for possible differences in SMRs across race/gender categories. ${ }^{25}$ Adjusted rates, including 95\% CIs, are reported. The mortality rates of youth offenders were also calculated by the severity of their involvement in the justice system (i.e., arrested, detained, 
incarcerated, or transferred). To compare rates across involvement in the justice system, Poisson regression analysis was conducted using death as the outcome and the log (number of years in the system) as an offset variable. The possible differential effects of justice involvement in different races was examined by testing a race by justice involvement interaction. Lastly, a survival analysis was conducted to model time to death from first arrest. Nonevents (i.e., if the youth did not die within the study period) and data beyond December 31, 2011, were censored. Predictors included age at first arrest, race/ethnicity, gender, and the youth's most serious justice system involvement. The proportional hazards assumption was tested using the Kolmogorov-type supremum test on 1,000 simulated samples. A significant $p$-value indicated that the variable did not meet the proportional hazards assumption. Severity of involvement in the justice system did not meet this assumption. Inspection of the survival curve revealed that the effect of this variable on youth mortality changed at Year 5, a change point confirmed by comparing the model's Akaike's information criterion values under all potential change points. The change point resulted in an alteration of the hazard function before and after the fifth year of observation, violating the proportional hazard assumption of the traditional Cox regression model. To accommodate, time-varying coefficients were introduced to the survival model. The justice system involvement variables had one set of hazard ratios (HRs) prior to Year 5 and then another set of HRs after Year 5. All analyses were performed using SAS, version 9.3.

\section{Results}

The sample of youth offenders included 49,479 adolescents and data were collected from 0.1 to 12.9 years after first arrest (mean, 7.3 years; median, 7.7 years; interquartile range, $4.0-10.8$ years). Aggregate exposure was 386,709 person-years.

Arrested youth represented the largest number of sampled youth $(30,678,62 \%)$, followed by detained
$(14,699,29 \%)$; incarcerated $(2,881,5 \%)$; and transferred youth $(1,221,2 \%)$ (Appendix Table 1 , available online). The majority of offenders were male, and the proportion of male offenders increased across the continuum of justice system involvement: $56 \%$ of arrested, $71 \%$ of detained, $76 \%$ of incarcerated, and $90 \%$ of youth transferred to adult court. Average youth age at first arrest was similar across the continuum (arrested, $14.9 \quad[\mathrm{SD}=1.8]$ years; detained, 14.4 $[\mathrm{SD}=1.8]$ years; incarcerated, $13.9[\mathrm{SD}=1.7]$ years; transferred, $14.7[\mathrm{SD}=1.9]$ years). Black youth comprised $47.5 \%$ of arrested, $52.5 \%$ of detained, $58.4 \%$ of incarcerated, and $68.5 \%$ of youth transferred to adult courts. Given that $28.4 \%$ of Marion County community residents are black, black youth were disproportionately represented at each point along the justice involvement continuum.

During the study period, 518 deaths occurred among youth offenders (Appendix Table 2, available online). The majority of deceased offenders were black $(56.0 \%)$ and male $(83.8 \%)$. The most common age of death was between 19 and 21 years (29.3\%; range, $12-30$ years). Most deaths were of individuals who were arrested (36.7\%) or detained $(41.7 \%)$ during the study period. Cause of death was found for $400(77.2 \%)$ of the 518 deceased youth offenders. The most common cause of death was homicide $(193,48.2 \%)$, followed by overdose (59, 14.7\%); other (54, 13.5\%; e.g., motor vehicle accidents, drowning, accidental shooting); suicide (47, 11.7\%); and natural causes (47, 11.7\%).

Mortality rates by youth race and gender are reported in Table 1 . Overall, the mortality rate was nearly 1.5 times higher among youth offenders than among community youth $(\mathrm{SMR}=1.48)$. The adjusted mortality rate for all

Table 1. Annual Mortality Rates, ${ }^{a}$ SMRs, and Adjusted Mortality Rates (95\% Cls)

\begin{tabular}{|c|c|c|c|c|c|}
\hline & Youth offenders & Community youth & SMR & Youth offenders, adjusted & $p$-value \\
\hline Total & $134(123,146)$ & $53(51,56)$ & $1.48(1.36,1.62)$ & $79(71,89)$ & $<0.001$ \\
\hline Male & $178(162,195)$ & $81(76,86)$ & $1.46(1.33,1.61)$ & $118(105,133)$ & $<0.001$ \\
\hline Black & $209(185,237)$ & $127(114,141)$ & $1.24(1.10,1.41)$ & $158(137,182)$ & $<0.001$ \\
\hline White & $155(133,181)$ & $59(54,65)$ & $2.23(1.90,2.59)$ & $131(112,155)$ & $<0.001$ \\
\hline Hispanic & $76(39,145)$ & $109(91,131)$ & $0.58(0.27,1.10)$ & $63(31,126)$ & 0.11 \\
\hline Female & $59(48,73)$ & $28(26,32)$ & $1.61(1.29,2.00)$ & $46(36,58)$ & $<0.001$ \\
\hline Black & $49(35,67)$ & $40(33,47)$ & $1.10(0.77,1.52)$ & $44(31,61)$ & 0.52 \\
\hline White & $75(56,100)$ & $26(22,30)$ & $2.56(1.88,3.45)$ & $67(49,91)$ & $<0.001$ \\
\hline Hispanic & $47(12,186)$ & $11(6,21)$ & $4.21(0.47,15.2)$ & $46(12,187)$ & 0.17 \\
\hline
\end{tabular}

Note: Boldface indicates statistical significance $(p<0.05)$.

${ }^{a}$ Per 100,000 person-years.

${ }^{b} p$-value corresponds to the significance testing of the $S M R=1.0$.

SMR, Standardized Mortality Ratio. 
Table 2. Annual Mortality Rates ${ }^{a}$ by Youth Justice System Involvement ( $\left.95 \% \mathrm{Cls}\right)$

\begin{tabular}{|c|c|c|c|c|c|}
\hline & Arrested & Detained & Incarcerated & Transferred & $p$-value ${ }^{b}$ \\
\hline Total & $90(78,104)$ & $165(144,188)$ & $216(171,274)$ & $313(232,422)$ & $<0.001$ \\
\hline Male & $123(105,145)$ & $210(182,242)$ & $248(192,320)$ & $318(233,433)$ & $<0.001$ \\
\hline Black & $133(105,168)$ & $241(200,290)$ & $264(192,354)$ & $402(289,560)$ & $<0.001$ \\
\hline White & $119(94,151)$ & $192(153,241)$ & $232(151,356)$ & $139(58,333)$ & 0.01 \\
\hline Female & $49(37,67)$ & $63(42,93)$ & $124(67,230)$ & $260(84,807)$ & 0.002 \\
\hline Black & $33(20,54)$ & $49(27,89)$ & $163(82,327)$ & $250(62,998)$ & $<0.001$ \\
\hline White & $74(51,105)$ & $74(42,131)$ & $66(16,262)$ & $308(43,2184)$ & 0.54 \\
\hline
\end{tabular}

Note: Boldface indicates statistical significance $(p<0.05)$.

${ }^{a}$ Per 100,000 person-years.

${ }^{b} p$-values are calculated from logistic regression models for each subgroup presented.

youth offenders was 79 per 100,000 person-years, compared with 53 deaths per 100,000 person-years among community youth. Gender by race differences were noted. Non-Hispanic whites' SMRs were higher than blacks' for both male (white, 2.23; black, 1.24) and female (white, 2.56; black, 1.10) offenders. Hispanic male offenders had the lowest SMR (0.58), whereas Hispanic female offenders had the highest SMR (4.21).

Mortality rates by the severity of youth involvement in the justice system, gender, and race are presented in Table 2 (per 100,000 person-years). Mortality rates by involvement in the justice system were calculated for white and black youth only because of low numbers of Hispanic offenders in the sample. The annual mortality rates differed significantly by severity of youth involvement in the justice system overall and for all subgroups except for white female offenders $(p=0.54)$. The risk ratios (RRs) comparing mortality by severity of youth involvement are presented in Appendix Table 3 (available online). Overall, youth transferred to adult court $(\mathrm{RR}=3.6,95 \% \mathrm{CI}=2.6,5.1)$; incarcerated $(\mathrm{RR}=2.5,95 \%$ $\mathrm{CI}=1.9,3.3)$; and detained $(\mathrm{RR}=1.9,95 \% \mathrm{CI}=1.5,2.3)$ had increased risk of death compared with arrested youth. Additionally, youth transferred to adult court $(\mathrm{RR}=1.9,95 \% \mathrm{CI}=1.5,2.3)$ and incarcerated $(\mathrm{RR}=1.3$, $95 \% \mathrm{CI}=1.01,1.8)$ were more likely to die than detained youth. This trend was similar among black male and female offenders. There were no significant differences in mortality across justice system involvement for white female youth, and the mortality for white male youth transferred to adult court did not differ significantly compared to other levels of youth system involvement.

Figure 1 shows Kaplan-Meier survival curves for youth involvement in the justice system. The survival curves diverged at 5 years. Prior to Year 5, there did not appear to be a difference in time to death based on severity of justice system involvement. By contrast, after
Year 5, as youth involvement in the justice system increased in severity so did the death rate. Results from the survival analysis are presented in Table 3. Male offenders were more likely to die than female offenders $(\mathrm{HR}=2.7,95 \% \mathrm{CI}=2.1,3.4)$, and older age was associated with an increased risk of death. For the first 5 years post arrest, only detained youth were at increased of risk of death compared to arrested youth $(\mathrm{HR}=1.6,95 \%$ $\mathrm{CI}=1.2,2.1)$. After Year 5, youth transferred to adult court $(\mathrm{HR}=3.3,95 \% \mathrm{CI}=2.3,4.9)$; incarcerated $(\mathrm{HR}=2.5$, $95 \% \mathrm{CI}=1.8,3.6)$; and detained $(\mathrm{HR}=1.7,95 \% \mathrm{CI}=1.2$, 2.2) were at increased risk of death compared to arrested youth. Black race and Hispanic ethnicity as predictors of time to death were only marginally significant. An interaction testing race/ethnicity (black or Hispanic) by justice system involvement was not significant.

\section{Discussion}

To date, this is the largest study of its kind to assess risk for early death among youth offenders by the level of their involvement in the justice system. The findings support past research showing that youth offenders face a significantly greater risk of death than community youth. ${ }^{1-5}$ A comparatively high rate of offender mortality was evident even among arrested youth whose involvement in the system is relatively common (one in three youth) $)^{12}$ and minimal (i.e., no time in a secure facility). Further, consistent with the study hypothesis, the data indicate that the greater the extent of an individual's justice system involvement, the greater the risk of death. Mortality rates increased incrementally along the continuum of justice system involvement (i.e., the mortality rate of arrested youth $<$ detained $<$ incarcerated $<$ transferred); transferred youth were more than three times as likely to die when compared with arrested youth. 


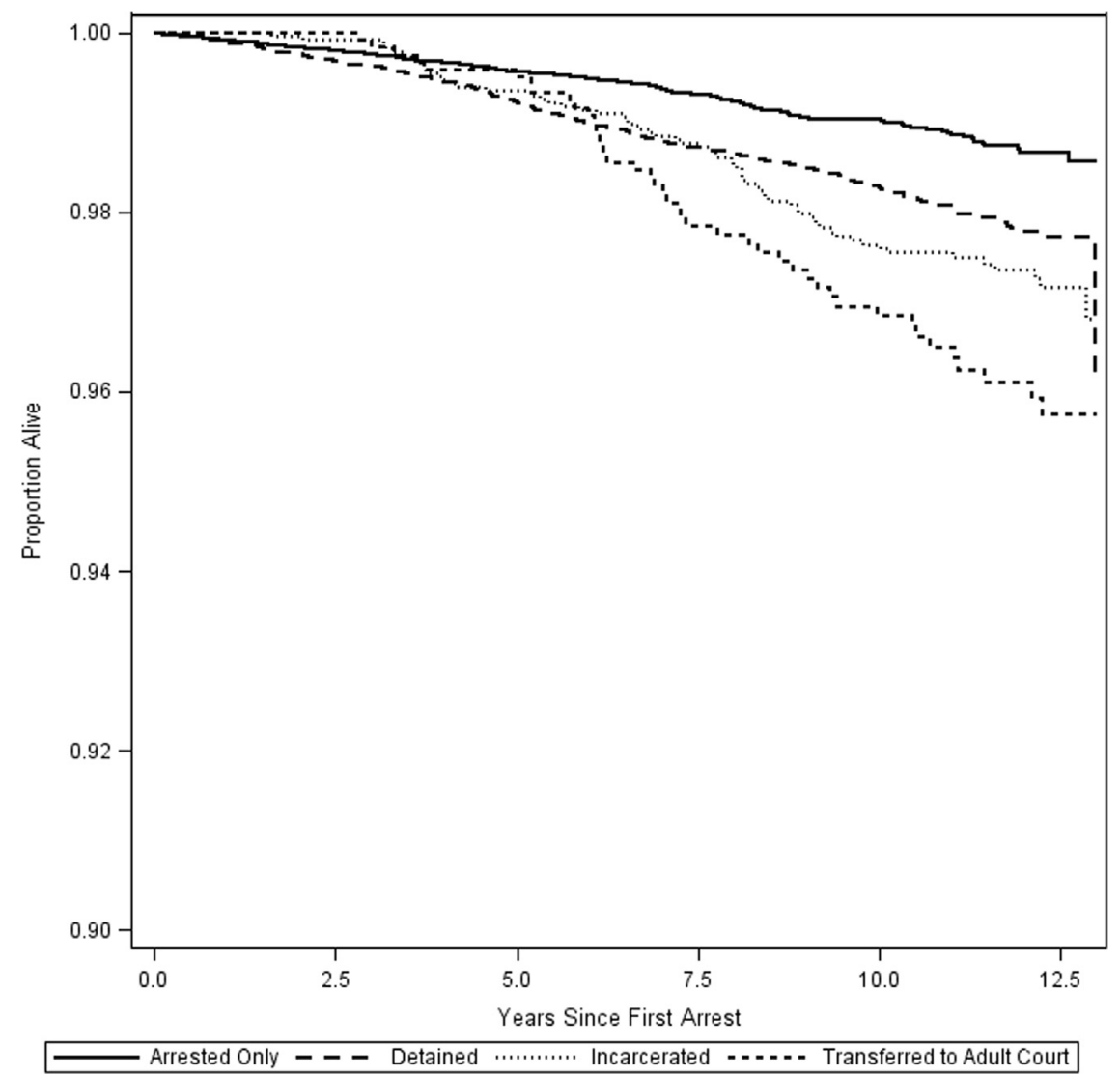

Figure 1. Kaplan-Meier survival curve for youth involvement in the criminal justice system.

Nearly half of all deaths among youth offenders were homicides. Teplin and colleagues ${ }^{6}$ similarly found that chronic offending is related to homicide risk, with $68 \%$ of deaths among detained youth resulting from homicide. The discrepancy between the homicide rate among offenders in Cook County (68\%) and the present study (48\%) may be partially attributed to the higher homicide rates reported by the Chicago Police Department compared with the Indianapolis Police Department (18.4 vs 13.5 per 100,000) across all age groups between 1999 and $2011^{26}$

The observed relationship between increased involvement in the system and mortality rates (most often due to homicide) is consistent with other research findings, suggesting a potential mechanism for the association. For example, among adult offenders, frequent, chronic criminal conduct has been associated with early and unnatural death. ${ }^{27}$ A recent longitudinal study found that youth who underwent official juvenile court processing (versus being diverted out of the justice system) had a higher rate of future violent and non-violent crimes and were more likely to have an adult criminal record. ${ }^{28}$ Moreover, in a 50-year follow-up study of both offenders and community youth, ${ }^{29}$ alcohol use and committing greater numbers of severe offenses were associated with higher mortality rates. Thus, continued crime warranting justice system intervention-beyond mere arrest-appears to increase exposure to life-anddeath situations.

These findings inform an understanding of the association between race and early mortality. First, although the SMRs did not vary by gender alone, SMRs among male youth varied substantially by race (1.24 among black male youth vs 2.23 among white male youth), confirming past studies showing that black male youth experience high rates of death in the community, regardless of justice system involvement. ${ }^{4-6}$ Second, black youth offenders experienced the clearest increase in mortality by severity of justice system involvement. Third, in the final proportional hazards model predicting time to death among offenders, race/ethnicity was only marginally significant for black and Hispanic youth. Moreover, the interaction between justice system involvement and race/ethnicity was not significant. This suggests that the severity of criminal justice involvement, rather than race/ethnicity, is a strong driver of early mortality among youth offenders. This finding clearly deserves more study. 
Table 3. Factors Associated With Mortality: Results From Survival Analysis

\begin{tabular}{|c|c|c|}
\hline Youth characteristics & $\begin{array}{c}\text { Hazard ratio } \\
(95 \% \mathrm{CI})\end{array}$ & $p$-value \\
\hline \multicolumn{3}{|l|}{ Age at first arrest (years) } \\
\hline $10-11$ (ref) & 1.00 & \\
\hline $12-14$ & $2.21(1.28,3.81)$ & 0.004 \\
\hline $15-16$ & 2.61 (1.51 4.49) & 0.001 \\
\hline $17-18$ & $3.65(2.09,6.35)$ & $<0.001$ \\
\hline \multicolumn{3}{|l|}{ Gender } \\
\hline Male & $2.71(2.14,3.44)$ & $<0.001$ \\
\hline Female (ref) & 1.00 & \\
\hline \multicolumn{3}{|l|}{ Race/ethnicity } \\
\hline Black & $1.19(1.00,1.43)$ & 0.053 \\
\hline Hispanic & $0.55(0.30,1.01)$ & 0.052 \\
\hline Other & $0.63(0.24,1.70)$ & 0.362 \\
\hline White (ref) & 1.00 & \\
\hline \multicolumn{3}{|c|}{ Justice system involvement (before 5 years) } \\
\hline Transferred to adult courts & $0.68(0.28,1.68)$ & 0.407 \\
\hline Incarcerated & $1.35(0.81,2.23)$ & 0.249 \\
\hline Detained & $1.62(1.23,2.14)$ & 0.001 \\
\hline Arrested (ref) & 1.00 & \\
\hline \multicolumn{3}{|c|}{ Justice system involvement (after 5 years) } \\
\hline Transferred to adult courts & $3.32(2.25,4.89)$ & $<0.001$ \\
\hline Incarcerated & $2.51(1.76,3.57)$ & $<0.001$ \\
\hline Detained & $1.65(1.24,2.18)$ & 0.001 \\
\hline Arrested (ref) & 1.00 & \\
\hline
\end{tabular}

Note: Boldface indicates statistical significance $(p<0.05)$.

\section{Limitations}

There are limitations to the current findings. Incomplete data linking of criminal and death records may have resulted in underestimation of mortality rates among youth offenders. However, the linking process was quite rigorous, and three separate data sources capturing youth deaths were utilized. Over roughly 35 years, almost 600 individuals have had their juvenile criminal records expunged in Marion County, excluding them from the analysis. Given this low rate of expungement, the authors estimate that their exclusion will have limited effects on the findings. The small sample of Hispanic youth limited the ability to meaningfully quantify their mortality across the continuum of justice system involvement. Previous research has shown that subtracting periods of incarceration from aggregate exposure among offenders may result in more representative mortality rates, as individuals are less likely to die in secure facilities. ${ }^{23}$ Given that stays could not be subtracted from data presented here, study results may be underestimates of the youth offender mortality rate. Lastly, other factors potentially related to early mortality that were not included in the current project (e.g., youth substance use) should be explored in future research.

\section{Conclusions}

Findings suggest that interventions for youth offenders should be tailored to the severity of youth involvement in the justice system. National efforts to reduce detentions (e.g., the Juvenile Detention Alternative Initiative) have decreased taxpayer costs ${ }^{30}$ and may also reduce youth mortality rates. Evidence-based violence prevention programs such as mentoring, ${ }^{31}$ afterschool programs, ${ }^{32}$ and school-based programming ${ }^{33}$ can effectively reach large numbers of arrested youth before they experience the increased risk of death associated with secure confinement. National organizations have repeatedly highlighted the need to reduce firearm violence, a leading cause of homicide-related death among adolescent and young adult populations. ${ }^{34-36}$ In light of these findings, violence prevention programs should focus narrowly on youth already held in secure facilities, as they are at significantly greater risk of death than arrested offenders. The successful CeaseFire program, for example, employs law enforcement strategies that target high-risk offenders. $^{37,38}$

The results highlight the need to address the interaction between race and justice system involvement in order to reduce high rates of death among youth offenders. It is well established that black youth, compared with white youth, are over-represented in the justice system and bear a disproportionate burden of death by homicide. For all youth, regardless of race, involvement in the justice system beyond arrest significantly increases risk of early, violent death. Continued intervention is necessary to redress these grim findings.

This study was funded by grants provided through the U.S. DHHS, Health Resources and Services Administration, Maternal and Child Health Research Program (R40MC08721) as well as the Agency for Healthcare and Quality (R01HS022681). The authors wish to thank the Marion County Superior Court, and specifically Judge Marilyn Moores, as well as the Marion County Sheriffs Office, for their support in completing this project. We would also like to thank P. Joseph Gibson, MPH, $\mathrm{PhD}$ and Stephen Clarke, $\mathrm{PhD}$ for their assistance in gathering 
mortality data from Marion County. Lastly, we would like to thank Andrew Alexander, Aaron Burgess, and Shawn Hoch for their help in the linking process.

This study was conducted in collaboration with local criminal justice and health agencies. The authors received no compensation in the conduct or writing of this manuscript. Findings and conclusions of this paper are those of the authors.

No financial disclosures were reported by the authors of this paper.

\section{References}

1. Coffey C, Wolfe R, Lovett AW, et al. Predicting death in young offenders: a retrospective cohort study. Med J Aust. 2004;181(9): 473-477.

2. Coffey C, Veit F, Wolfe R, Cini E, Patton GC. Mortality in young offenders: retrospective cohort study. $\mathrm{Br}$ Med J. 2003;326:1064. http: //dx.doi.org/10.1136/bmj.326.7398.1064.

3. Ezell ME, Tanner-Smith EE. Examining the role of lifestyle and criminal history variables on the risk of homicide victimization. Homicide Stud. 2009;13(2):144-173. http://dx.doi.org/10.1177/108 8767908330493.

4. Ramchand R, Morral AR, Becker K. Seven-year life outcomes of adolescent offenders in Los Angeles. Am J Public Health. 2009;99 (5):863-870. http://dx.doi.org/10.2105/AJPH.2008.142281.

5. Teplin LA, McClelland GM, Abram KM, Mileusnic D. Early violent death among delinquent youth: a prospective longitudinal study. Pediatrics. 2005;115(6):1586-1593. http://dx.doi.org/10.1542/peds.2004-1459.

6. Teplin LA, Jakubowski JA, Abram KM, et al. Firearm homicide and other causes of death in delinquents: a 16-year prospective study. Pediatrics. 2014;134(1):63-73. http://dx.doi.org/10.1542/peds.20133966.

7. Parks SE, Johnson LL, McDaniel DD, Gladden M. Surveillance for violent deaths-National Violent Death Reporting System, 16 states, 2010. Morb Mortal Wkly Rep. 2014;63:1-33.

8. Jordan KL, Freiburger TL. Examining the impact of race and ethnicity on the sentencing of juveniles in the adult court. Crim Justice Policy Rev. 2010;21(2):185-201. http://dx.doi.org/10.1177/0887403409354 738.

9. Leiber MJ, Fox KC. Race and the impact of detention on juvenile justice decision making. Crime Delinq. 2005;51(4):470-497. http://dx. doi.org/10.1177/0011128705275976.

10. Pope CE, Lovell R, Hsia HM. Disproportionate Minority Confinement: A Review of the Research Literature from 1989 through 2001. Washington, DC: US Department of Justice, Office of Justice Programs, Office of Juvenile Justice and Delinquency Prevention; 2002.

11. David-Ferdon C, Dahlberg LL, Kegler SR. Homicide rates among persons aged 10-24 years-United States, 1981-2010. Morb Mortal Wkly Rep. 2013;62:545-560.

12. Brame R, Turner MG, Paternoster R, Bushway SD. Cumulative prevalence of arrest from ages 8 to 23 in a national sample. Pediatrics. 2012;129(1):21-27. http://dx.doi.org/10.1542/peds.2010-3710.

13. Braverman PK, Murray PJ. Health care for youth in the juvenile justice system. Pediatrics. 2011;128(6):1219-1235. http://dx.doi.org/10.1542/ peds.2011-1757.

14. Goldstrom I, Jaiquan F, Henderson M, Male A, Mandersheid R. The Availability of Mental Health Services to Young People in Juvenile Detention and Confinement Facilities: A National Survey. Washington, DC: Center for Mental Health Services, 2000.

15. Pajer KA, Kelleher K, Gupta RA, Rolls J, Gardner W. Psychiatric and medical health care policies in juvenile detention facilities. J Am Acad
Child Adolesc Psychiatry. 2007;46(12):1660-1667. http://dx.doi.org/ 10.1097/chi.0b013e318157d2da.

16. Ng IY, Shen X, Sim H, et al. Incarcerating juveniles in adult prisons as a factor in depression. Crim Behav Ment Health. 2011;21(1):21-34. http: //dx.doi.org/10.1002/cbm.783.

17. Lambie I, Randell I. The impact of incarceration on juvenile offenders. Clin Psychol Rev. 2013;33(3):448-459. http://dx.doi.org/10.1016/j.cpr. 2013.01.007.

18. Dumont DM, Allen SA, Brockmann BW, Alexander NE, Rich JD. Incarceration, community health, and racial disparities. J Health Care Poor Underserved. 2013;24(1):78-88. http://dx.doi.org/10.1353/hpu.2013. 0000.

19. Profile of general population and housing characteristics: 2010 Marion County, Indiana. 2010 Demographic Profile Data. US Department of Commerce, US Census Bureau, 2010. http://factfinder.census.gov/ faces/tableservices/jsf/pages/productview.xhtml?src=bkmk. Accessed April 22, 2015.

20. McDonald CJ, Overhage JM, Tierney P, et al. The Regenstrief Medical Record System: a quarter century experience. Int J Med Inform. 1999; 54(3):225-253. http://dx.doi.org/10.1016/S1386-5056(99)00009-X.

21. McDonald CJ, Overhage JM, Barnes M, et al. INPC Management Committee. The Indiana Network for Patient Care: a working local health information infrastructure. Health Aff. 2005;24(5):1214-1220. http://dx.doi.org/10.1377/hlthaff.24.5.1214.

22. Grannis SJ, Overhage JM, Hui S, McDonald CJ. Analysis of a probabilistic record linkage technique without human review. AMIA Annu Symp Proc. 2003;2003:259-263.

23. Zlodre J, Fazel S. All-cause and external mortality in released prisoners: systematic review and meta-analysis. Am J Public Health. 2012;102(12) e67-e75. http://dx.doi.org/10.2105/AJPH.2012.300764.

24. Rothman KJ, Greenland S, Lash TL, eds. Modern Epidemiology. Philadelphia, PA: Lippincott Williams \& Wilkins, 2008.

25. Breslow NE, Day NE. Statistical Methods in Cancer Research. Lyon, France: International Agency for Research on Cancer, 1987.

26. Crime in the United States. Washington, DC: U.S. Department of Justice, Federal Investigation Bureau, Criminal Justice Information Services Division; 2013. www.fbi.gov/about-us/cjis/ucr/crime-in-the-u.s/ 2013/crime-in-the-u.s.-2013. Accessed December 5, 2014.

27. Nieuwbeerta P, Piquero AR. Mortality rates and causes of death of convicted Dutch criminals 25 years later. J Res Crime Delinq. 2008; 45(3):256-286. http://dx.doi.org/10.1177/0022427808317573.

28. Petitclerc A, Gatti U, Vitaro F, Tremblay RE. Effects of juvenile court exposure on crime in young adulthood. J Child Psychol Psychiatry. 2013;54(3):291-297. http://dx.doi.org/10.1111/j.1469-7610.2012.026 16.x.

29. Laub JH, Vaillant GE. Delinquency and mortality: a 50-year follow-up study of 1,000 delinquent and nondelinquent boys. Am J Psychiatry. 2000;157(1):96-102. http://dx.doi.org/10.1176/ajp.157.1.96.

30. Seigle E, Walsh N, Weber J. Core Principles for Reducing Recidivism and Improving Other Outcomes for Youth in the Juvenile Justice System. New York: Council of State Governments Justice Center; 2014.

31. Tolan P, Henry D, Schoeny M, Bass A. Mentoring interventions to affect juvenile delinquency and associated problems. Campbell Syst Rev. 2008:16.

32. Durlak JA, Weissberg RP, Pachan M. A meta-analysis of after-school programs that seek to promote personal and social skills in children and adolescents. Am J Community Psychol. 2010;45(3-4):294-309. http://dx. doi.org/10.1007/s10464-010-9300-6.

33. Inman DD, van Bakergem KM, LaRosa AC, Garr DR. Evidence-based health promotion programs for schools and communities. Am J Prev Med. 2011;40(2):207-219. http://dx.doi.org/10.1016/j.amepre.2010.10.031.

34. American College of Preventive Medicine. Preventing handgun injury: American college of Preventive Medicine position statement. Am J Prev Med. 2002;23(4):314-316. http://dx.doi.org/10.1016/S0749-3797(02) 00520-2. 
35. Council on Injury. Violence, Poison Prevention Executive Committee. Firearm-related injuries affecting the pediatric population. Pediatrics. 2012;130(5):e1416-e1423. http://dx.doi.org/10.1542/peds. 2012-2481.

36. Duke N, Resnick MD, Borowsky IW. Adolescent firearm violence: position paper of the society for adolescent medicine. J Adolesc Health. 2005;37(2):171-174. http://dx.doi.org/10.1016/j.jadohealth.2005.05. 001.

37. Braga AA, Weisburd DL. The effects of focused deterrence strategies on crime: a systematic review and meta-analysis of the empirical evidence. J Res Crime Delinq. 2012;49(3):323-358. http://dx.doi.org/10. $1177 / 0022427811419368$.
38. Whitehill J, Webster D, Frattaroli S, Parker E. Interrupting violence: how the CeaseFire Program prevents imminent gun violence through conflict mediation. J Urban Health. 2014;91(1):84-95. http://dx.doi. org/10.1007/s11524-013-9796-9.

\section{Appendix}

\section{Supplementary data}

Supplementary data associated with this article can be found at http://dx.doi.org/10.1016/j.amepre.2015.08.030. 